\title{
Investigation of Thermoplastic Polyurethanes Synthesized via Two Different Prepolymers
}

\author{
Paulina Kasprzyk $^{1}$ - Ewelina Sadowska ${ }^{1}$ Janusz Datta ${ }^{1}$ (])
}

Published online: 26 August 2019

(c) The Author(s) 2019

\begin{abstract}
The man aim of this work was to investigate the effect of the molecular weight of polyols, mixture of prepolymers, and $[\mathrm{NCO}] /[\mathrm{OH}]$ molar ratio used during the prepolymer chain extending step on the chemical structure, thermomechanical and mechanical properties, and thermal stability of thermoplastic poly(ether-urethane)s In this work thermoplastic poly(etherurethane)s were synthesized by using polyols with a various molecular weight, 4,4'-diphenylmethane diisocyanate and biobased glycol. Materials were obtained by a two-step method. The tests were carried out for polyurethanes obtained from a mixture of prepolymers and for reference samples. In the case of materials obtained with using mixture of prepolymers, the ratio of both prepolymers was determined on 50/50 weight percent. Soft segments of materials prepared with using mixture consist of two different polyols. The chemical structure was analyzed using FTIR spectroscopy. The Gaussian deconvolution technique was used to study the hydrogen bonding as well as to decompose carbonyl region of three peaks in various TPUs. The thermal degradation behavior was investigated by using thermogravimetric analysis at heating rates of $10^{\circ} \mathrm{C} /$ min. It was confirmed that the mixture of prepolymers has an effect of the degree of phase separation, thermal stability and selected properties of synthesized thermoplastic poly(ether-urethane)s.
\end{abstract}

Keywords Phase separation - Thermogravimetric analysis · Thermoplastic polyurethanes · Mechanical properties · Activation energy analysis

\section{Introduction}

The growing demand for plastics, including polyurethanes, and the associated increasing pollution of the natural environment, have contributed to take the necessary steps to solve global environmental problems. To reduce carbon dioxide emission, new technology is being developed that uses materials from renewable or recycled resources, as much as possible, instead of materials obtained directly from crude oil [1-3]. The stricter legal regulations regarding the limitation of the use of disposable plastics, as well as the increased interest of the public in the protection of

Electronic supplementary material The online version of this article (https://doi.org/10.1007/s10924-019-01543-7) contains supplementary material, which is available to authorized users.

Janusz Datta

janusz.datta@pg.edu.pl

1 Department of Polymers Technology, Faculty of Chemistry, Gdańsk University of Technology, 11/12 Gabriela Narutowicza Street, 80-233 Gdańsk, Poland the natural environment, cause that the chemical industry is looking for new solutions based on natural origin raw materials $[4,5]$. Therefore, the current trend is to replace petrochemical polyols used in the synthesis of polyurethanes by polyols obtained from biomass, in which case sugars, vegetable oils and lignin are being used [6,7].

The basic group of polyurethane materials are thermoplastic polyurethanes (TPUs), which contain repeating units of hard segments (HS) and soft segments (SS) $[8,9]$. In terms of morphology, it is a two-phase system consisting of hard microdomains distributed in a flexible and continuous matrix. Self-organization of hard segment domains is the result of thermodynamic incompatibility between components and occurs through physical interactions $[10,11]$. Microphase separation determines a number of TPUs properties. As a result, the material is characterized by the presence of two glass transition temperatures $\left(\mathrm{T}_{\mathrm{g}}\right)$. Hard segments (HS) are elements of the structure with high glass transition temperature $\left(\mathrm{T}_{\mathrm{g}}\right)$ and high modulus, thus exhibiting less flexibility at room temperature compared to soft segments (SS) with low glass transition 
temperature $\left(\mathrm{T}_{\mathrm{g}}\right)$ and also characterized by melting point $\left(T_{m}\right)$ [12]. However, the ideal phase separation is never achieved. Hard segments (HS) always partially mix with soft segments (SS), and the glass transition temperatures $\left(\mathrm{T}_{\mathrm{g}}\right)$ depend on the degree of microphase separation $[10$, 13].

There are many factors that determine the degree of phase separation, such as the chemical structure of components, the average molecular weight of polyols, the ratio of hard to soft segments and their crystallinity, etc. [14]. Meanwhile, the reason for this phenomenon is primarily the existence of hydrogen bonds between the polymer chains, which through the strong bonding of hard segments lead to increased phase separation [14-16]. Unfortunately, hydrogen bonds are redistributed due to thermal effects, thus the thermal stability of TPUs is limited [16]. Therefore, determining the temperature at which TPUs can be used without significant reduction in properties plays a crucial role in high-temperature applications as well as in determining the correct processing conditions [17, 18]. It should be remembered that thermal degradation of polyurethanes is a complex process, initiated at the urethane groups of hard segments and ending by breaking ester or ether bonds in soft segments $[17,19,20]$. Depending on the chemical structure of the polyol and the isocyanate, thermal decomposition of TPU takes place at different temperatures, which can reach $250{ }^{\circ} \mathrm{C}[19,20]$. It is worth to mention that the thermal stability of poly(esterurethane)s is higher than that of poly(ether-urethane)s [19]. Furthermore, the crosslink density and the concentration of urethane groups are also important in degradation processes [17].

In this study, we report the synthesis of innovative biobased TPUs using a mixture of prepolymers. We prepared also two references samples. First reference material was based on polyols with a molecular weight of $1000 \mathrm{~g} / \mathrm{mol}$, and second material was based on polyols with $\mathrm{Mw}=2700 \mathrm{~g} /$ mol. In the case of polyurethanes with a soft segments structure consisting of two polyols, the ratio of both different prepolymers was determined on 50/50 weight percent. We mixed two different prepolymers, from which first was prepared with using polyol PO3G1000 and second was based on polyol PO3G2700.

The aim of the study was to determine how the mixture of prepolymers affects the individual materials properties. For this purpose, the structure of synthesized polyurethanes was examined by FTIR and NMR analyses. In the next step, thermal, mechanical and processing properties were determined with the use methods such as TGA, DMTA, static mechanical test. According to the literature, TPUs can be processed by thermoplastic techniques such as injection molding, extrusion or blow molding. In order to confirm the thermoplastic character of the prepared materials, we determined the melt flow index. All tests were carried out for polyurethanes obtained from a mixture of prepolymer and for reference samples.

Obtained results will complete scientific literature for the results related to the materials obtained by using mixture of prepolymers. Besides, the researches allowed to determine the influence of mixture of prepolymers, content of hard segment and length of polyol on the properties materials. The synthesized materials can be used as typical thermoplastic materials by polymers industry.

In our previously works, we prepared materials with using one prepolymers. Additionally, our previously work was focused on confirmation of the possibility of use biobased monomer to the synthesis of TPUs. We had examined the influence of molar ratio $[\mathrm{NCO}] /[\mathrm{OH}]$ groups on the chemical structure, mechanical and dynamic-mechanical properties of TPUs. The main innovation of this work is synthesis materials with using mixture of prepolymers. The aim of this study was to determine influence the mixture of prepolymers on the properties synthesized materials, especially chemical structure, thermal stability, processing and dynamic-mechanical properties.

\section{Experiments}

\section{Materials}

Thermoplastic poly(ether-urethane)s were synthesized with the use of natural raw materials: bio-polyols and bio-glycol. Bio-based poly(trimethylene glycol) PO3Gs $\left(M_{\mathrm{n}}=1000 \mathrm{~g} /\right.$ mol or $M_{\mathrm{n}}=2700 \mathrm{~g} / \mathrm{mol}$ ) were provided by Allesa (Germany), while bio-based 1,4-butanediol BDO was supplied by BASF (Germany). Both bio-PO3G and bio-BDO were obtained by corn sugar fermentation process with using Escherichia coli bacteria. Aromatic diisocyanate 4,4'-diphenylmethane diisocyanate MDI was purchased from BorsedChem (Hungary) and the catalyst DABCO was purchased from Sigma-Aldrich (Poland).

\section{Preparation of Bio-thermoplastic Poly(ether-urethane)s}

Thermoplastic poly(ether-urethane)s based on polyols with a molecular weight of $1000 \mathrm{~g} / \mathrm{mol}$ and $2700 \mathrm{~g} / \mathrm{mol}$, and the mixture of prepolymers, were obtained by a twostep method (Fig. 1). The polymerization was carried out in two reactors under the same conditions. First, different molecular weight bio-polyols were degassed under vacuum for $2 \mathrm{~h}$ at $95^{\circ} \mathrm{C}$ to remove the moisture contained therein. Then, in order to synthesize the urethane prepolymers, MDI and a small amount of the stabilizer were added to the dried PO3Gs. The prepolymerization was carried out for $3 \mathrm{~h}$ while the temperature was maintained at $85^{\circ} \mathrm{C}$. The 


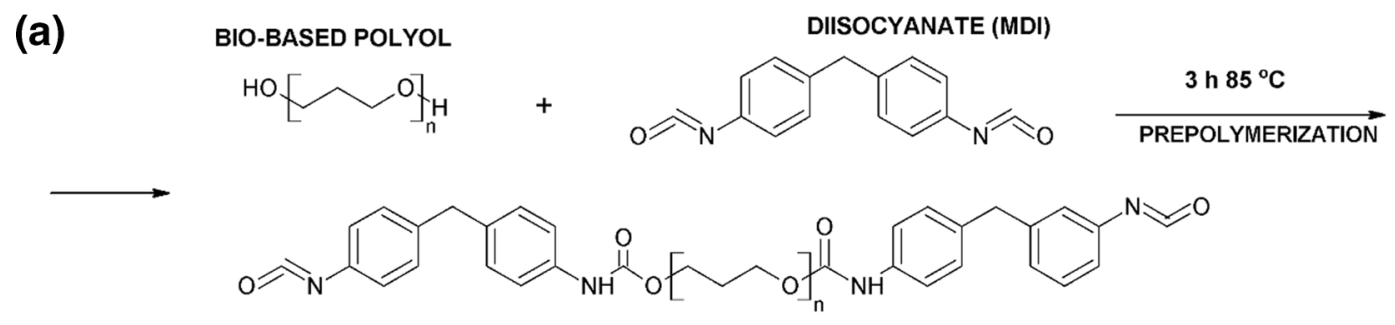

(b)

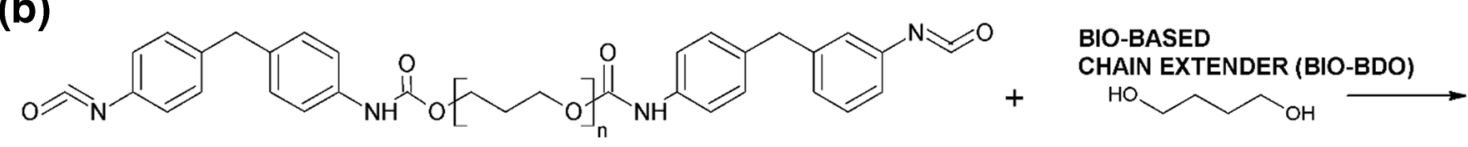

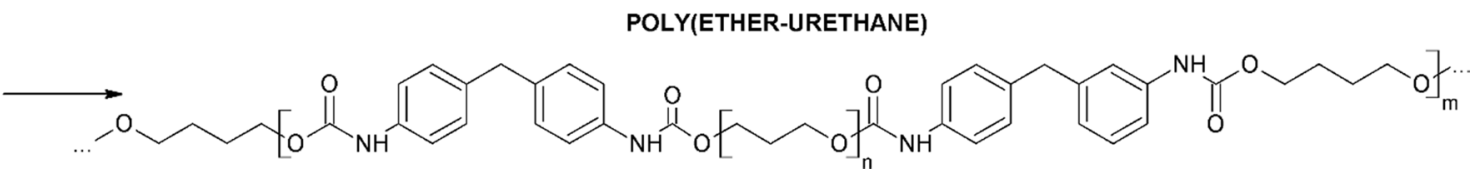

Fig. 1 Synthesis of bio-based thermoplastic poly(ether-urethane)s by the prepolymer method

prepolymers were synthesized with an excess of isocyanate groups of $10 \%$, which was determined in accordance to ISO 14896:2010 standard. In the next step, the urethane prepolymers chains and the prepolymers mixture chains were extended with bio-based BDO, using $0.3 \%$ DABCO as a catalyst. In the case of polyurethanes with a soft segments structure consisting of two polyols, the ratio of both different prepolymers was determined on 50/50 weight percent. The obtained samples differed from each other by the molar ratio of $[\mathrm{NCO}] /[\mathrm{OH}]$ groups, which was $0.9,0.95$ and 1.0 (Table 1). Finally, the structure of the thermoplastic poly(ether-urethane)s was established during curing in a laboratory dryer at $100{ }^{\circ} \mathrm{C}$ for $24 \mathrm{~h}$.

In the further part of the work, prepared bio-based thermoplastic poly(ether-urethane)s are encoded with appropriate symbols. The first part of the symbol corresponds to the polyol used during synthesis, while the second part determines $[\mathrm{NCO}] /[\mathrm{OH}]$ molar ratio. For example, the material marked as PO3G1000_0.9 was obtained from a polyol with a molecular weight equal to $1000 \mathrm{~g} / \mathrm{mol}$ and at the [NCO]/ [OH] molar ratio of 0.9 , whereas PO3Gmix_0.9 was synthesized using a different molecular weights mixture of prepolymers.

\section{Methods}

The chemical structure of the synthesized polyurethanes was confirmed through Fourier transform infrared spectroscopy using a Nicolet FTIR 8700 spectrophotometer (Thermo Electron Co., USA). The infrared spectra were recorded in the wavelength range from 500 to $4500 \mathrm{~cm}^{-1}$, with 64 scans
Table 1 The formulation design of bio-based thermoplastic polyurethane samples

\begin{tabular}{llll}
\hline Samples & $\begin{array}{l}{[\mathrm{NCO}] /[\mathrm{OH}]} \\
\text { molar ratio }\end{array}$ & $\begin{array}{l}\text { HS content } \\
(\mathrm{wt} \%)^{\mathrm{a}}\end{array}$ & $\begin{array}{l}\text { Content of bio- } \\
\text { based sources } \\
(\mathrm{wt} \%)^{\mathrm{b}}\end{array}$ \\
\hline PO3G1000_0.95 & 0.95 & 49.4 & 60.5 \\
PO3G2700_0.95 & 0.95 & 42.1 & 67.8 \\
PO3Gmix_0.9 & 0.90 & 46.1 & 64.3 \\
PO3Gmix_0.95 & 0.95 & 45.8 & 64.1 \\
PO3Gmix_1.0 & 1.00 & 45.5 & 64.0 \\
\hline
\end{tabular}

${ }^{\text {a}}$ Hard segment concentration is defined as the ratio of the mass of non-polyol components to the total mass of the polymer

${ }^{b}$ Bio-content is defined as the ratio of the mass of bio-based components to the total mass of the polymer

and a device resolution of $4 \mathrm{~cm}^{-1}$. The analyzed samples were a thin solid state. The measurement took place at room temperature, and the degree of phase separation (DPS) as well as the degree of phase mixing (DPM) was calculated according to the following equations [21].

$D P S=\frac{R}{R+1}$,

$D P M=1-D P S$,

$R=\frac{A_{b}}{A_{f}}$,

where: $R$ is the carbonyl hydrogen bonding index; $A_{b}$ is the absorption intensity of hydrogen-bonded carbonyl, and $A_{f}$ stands for the absorption intensity of free carbonyl. 
Hydrogen Nuclear Magnetic Resonance Spectroscopy $\left({ }^{1} \mathrm{H}\right.$ NMR) was used to study the chemical structure of biobased thermoplastic poly(ether-urethane)s. The ${ }^{1} \mathrm{H}$ NMR spectra of the synthesized materials were recorded via a Varian Mercury Vx spectrometer. The measurement was carried out at room temperature, whereas the operating frequency of the spectrometer was $400 \mathrm{MHz}$. The spectrum was obtained with the use of d-DMSO as a solvent. The ${ }^{1} \mathrm{H}$ NMR spectra (Figs. S1, S2) and discussion can be found in the Supplementary Information.

Thermogravimetric Analysis (TGA) of prepared bio-based thermoplastic poly(ether-urethane)s was performer using NETZSCH TG 209F1 Libra analyzer. The samples were heated from 25 to $700{ }^{\circ} \mathrm{C}$ at a rate of $10{ }^{\circ} \mathrm{C} / \mathrm{min}$. The measurements were realized under nitrogen atmosphere. The samples mass was around $10 \mathrm{mg}$.

Dynamic mechanical thermal analysis (DMTA) was carried out in accordance with ASTM D4065:2012 using the DMA Q800 analyzer (TA Instruments). The samples of materials in the form of rectangles with dimensions: $10 \mathrm{~mm}$ wide, $40 \mathrm{~mm}$ long and $2 \mathrm{~mm}$ thick were prepared for the study. The temperature range of the measurement was from -100 to $150^{\circ} \mathrm{C}$, while the heating rate was set at $4{ }^{\circ} \mathrm{C} / \mathrm{min}$, and the frequency at $10 \mathrm{~Hz}$. The measurement provided information in regard to the change of storage modulus ( $\left.\mathrm{E}^{\prime}\right)$, loss modulus $\left(\mathrm{E}^{\prime \prime}\right)$ and tan delta $(\tan \delta)$ as a function of temperature. The glass transition temperature of the flexible segments $\left(\mathrm{T}_{\mathrm{gSS}}\right)$ was determined based on the maximum $\tan \delta$ peak.

Static tensile properties (tensile strength and elongation at break) were determined with the use of Zwick/Roell Z020 universal testing machine, according to ISO 37:2007 standard. The dumbbell specimens were stretched at a cross-head speed of $100 \mathrm{~mm} / \mathrm{min}$, at room temperature. Based on the recorded stress and strain, the tensile strength, elongation at break and Young's modulus of TPUs were investigated.

The hardness measurement of the obtained thermoplastic poly(ether-urethane)s was carried out using an electronic Shore type D Durometer, in accordance with ISO 868:2005 standard. The results were determined as the average of ten measuring points situated in different areas of the sample.

The melt flow rate index (MFI) of TPUs samples was examined by Zwick/Roell plastometer, according to ISO 1133:2011. The measurement was performed at three different temperatures, applying $5 \mathrm{~kg}$ load. The graphs needed to calculate the activation energy $\left(\mathrm{E}_{\mathrm{a}}\right)$ of the melting flow determined by the Eq. (4) were plotted using data from the device [22]. A linear relationship between MFI and temperature was obtained by matching the regression line, which slope coefficient corresponds to the value of $E_{a} / R$, where $R$ is the universal gas constant.

$\ln (M F R)=\ln (k)-\frac{E_{a}}{R T}$

\section{Results and Discussion}

\section{FTIR}

The FTIR-ATR analysis was used to confirm the chemical structure of thermoplastic polyurethane samples, as well as to determine the correlation between the calculated degree of phase separation and the materials properties. All FTIR spectra were normalized. In the FTIR spectra (see Fig. 2a, b) there is no absorption band at the $2270 \mathrm{~cm}^{-1}$ related to NCO groups and also at $3300-3500 \mathrm{~cm}^{-1}$ corresponding to $\mathrm{OH}$ groups, and thus it can be concluded that the components are completely reacted $[23,24]$. At the wavenumber range from 3380 to $3230 \mathrm{~cm}^{-1}$, there are the $-\mathrm{NH}$ stretching vibrations of the urethane group in the area of hydrogen bonds [25]. The $\mathrm{C}=\mathrm{O}$ stretching vibrations commonly referring to the amide-I region occur at $1670-1750 \mathrm{~cm}^{-1}$. The peak at $1730 \mathrm{~cm}^{-1}$ assign to the free carbonyl group, while at $1699 \mathrm{~cm}^{-1}$ to the hydrogen bounded carbonyl group in crystalline phase of hard segment domains. Moreover, the hydrogen bounded $\mathrm{C}=\mathrm{O}$ group stretching band associated with the amorphous phase is unnoticeable [11, 22, 26]. Normalized fragments of the FTIR spectrums in the range of the occurrence of the multiple band and the $\mathrm{N}-\mathrm{H}$ groups absorption band are shown in Fig. 3a, b. According to literature reports, the absorption band at the carbonyl groups in crystalline region increases with the increasing content of hard segments. This coincides with the relationship shown in the Fig. 3a, where the intensity of the peak increases when the $[\mathrm{NCO}] /[\mathrm{OH}]$ molar ratio decreases. This behavior is explained by the formation of larger HS domains whose presence results in improved hard and soft segment separation [26]. Furthermore, the same relationship can be attributed also to the $-\mathrm{NH}$ stretching vibrations. It is also worth noting (see Fig. 3b) that the intensity of the peak associated with free carbonyl groups region is significantly influenced by prepolymer structure. In addition, the intensity of the peaks at $1699 \mathrm{~cm}^{-1}$ and $1730 \mathrm{~cm}^{-1}$ is clearly higher for the prepolymers mixture compared to TPUs synthesized based on different molecular weights polyols. Continuing the spectrum analysis, it can be concluded that the peak at $2900 \mathrm{~cm}^{-1}$ corresponds to the asymmetric vibrations of the $\mathrm{CH}_{2}$ groups, while the symmetric vibrations of the $\mathrm{CH}_{2}$ groups occurred at $2858 \mathrm{~cm}^{-1}$. Deformation vibration of the $\mathrm{C}-\mathrm{H}$ groups is appeared around $1414 \mathrm{~cm}^{-1}$. The absorption band at $1529 \mathrm{~cm}^{-1}$ is the result of $-\mathrm{CN}$ stretching vibrations, and at $1597 \mathrm{~cm}^{-1}$ is correspond to $\mathrm{N}-\mathrm{H}$ bending vibrations. There is intense peak at $1066 \mathrm{~cm}^{-1}$ is connected with the $\mathrm{C}-\mathrm{O}-\mathrm{C}$ stretching vibration of the aliphatic polyether. However, in this region besides the peak connected with symmetric stretching of ether group, there is also less intense peak at $1221 \mathrm{~cm}^{-1}$ assigned to $\mathrm{C}-\mathrm{O}-\mathrm{C}$ asymmetric 


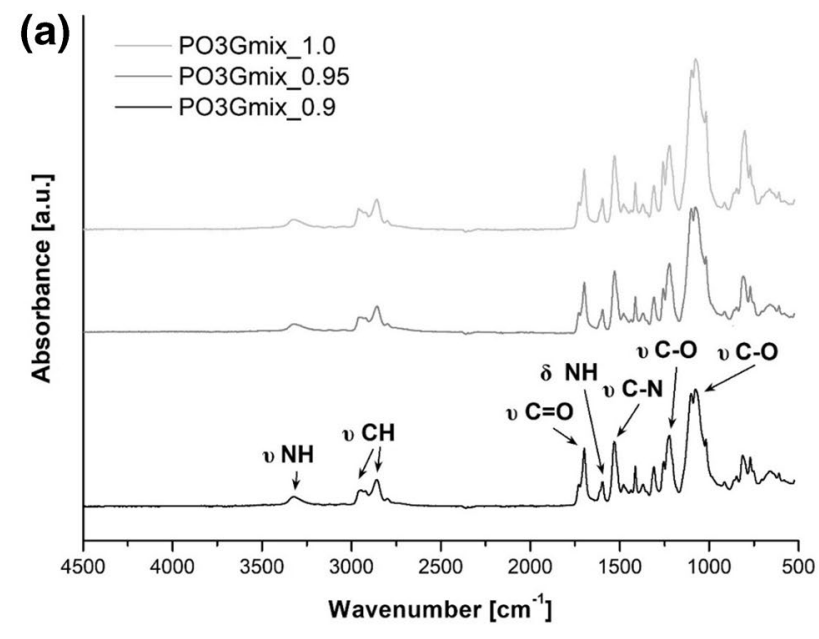

(b)

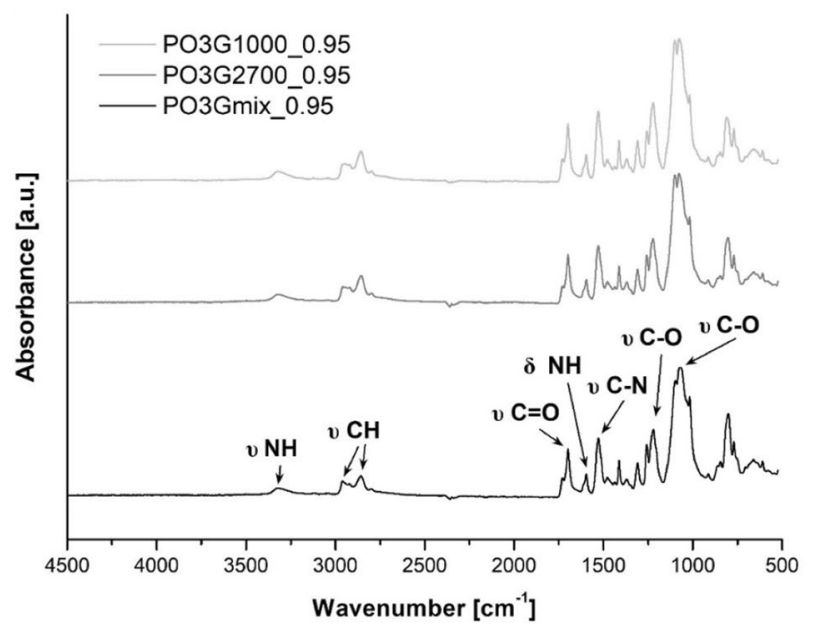

Fig. 2 a FTIR spectra of TPUs obtained with using the mixture of prepolymers, b FTIR spectra of materials with $[\mathrm{NCO}] /[\mathrm{OH}]$ molar ratio of 0.95 during the prepolymer chain extension step

stretching $[27,28]$. In conclusion, it can be deduced that the bio-based obtained materials have a similar chemical structure, and small shifts at the wavenumber can be caused by varying HS content.

The degree of phase separation in hard segments was determined by deconvolution the carbonyl peaks found on the infrared spectra in the $1660-1760 \mathrm{~cm}^{-1}$ range. The Origin software was used to analyze these areas, and the obtained results were presented in Table 2. Considering DPS and DPM, it can be concluded that all produced materials are characterized by good phase separation, which reaches over $80 \%$. A smaller part of the segments interacts better with each other, which is proved by the fact that less than $20 \%$ of HS is well dispersed in the polyol matrix. Only a small differences were observed in the position of the carbonyl peaks for all TPUs samples, which indicates their similarity. However, the individual samples

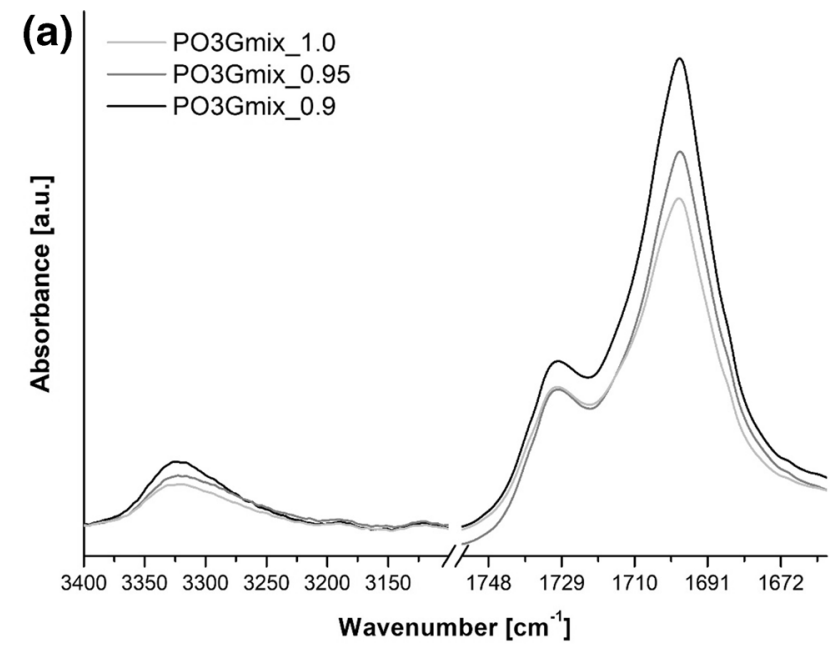

(b)

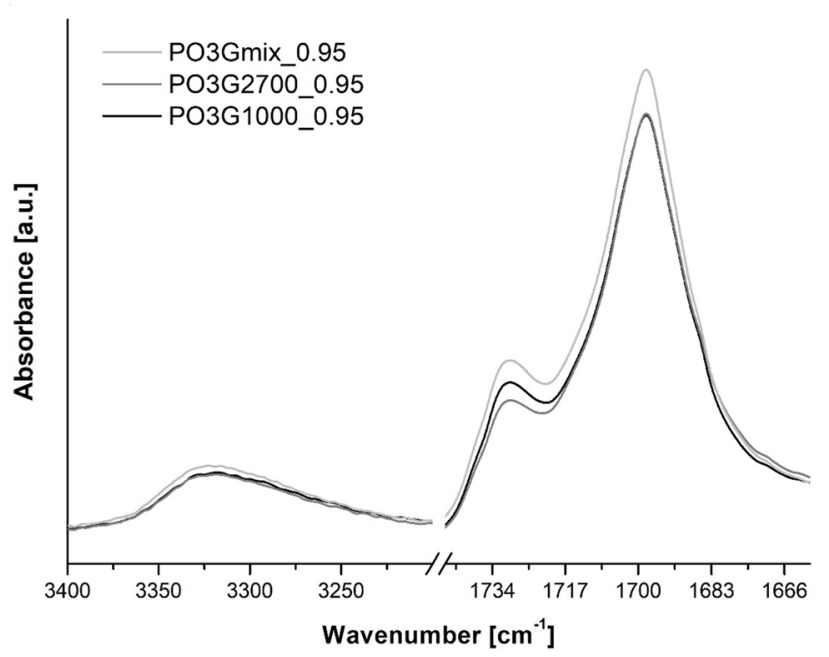

Fig. 3 Part of the FTIR spectrum with $\mathrm{N}-\mathrm{H}$ and $\mathrm{C}=\mathrm{O}$ absorption bands for $\mathbf{a}$ TPUs obtained with using the mixture of prepolymers, $\mathbf{b}$ materials with $[\mathrm{NCO}] /[\mathrm{OH}]$ molar ratio of 0.95 during the prepolymer chain extension step

differ from each other in the number of hydrogen bounded and free carbonyl groups. The largest amount of hydrogen bonds in crystalline region formed in the PO3G2700_0.95 structure, hence the highest degree of separation between the hard and soft segments present in this sample. Comparing our previous work, it is visible, that DPS dependent on the length of used polyols. Materials prepared with using polyol $\mathrm{M}_{\mathrm{w}}=2000 \mathrm{~g} / \mathrm{mol}$, (\% $\mathrm{NCO}$ in prepolymer equal $6 \%$ ) posses $31.8 \%$ of HS and showed DPS equal 0.640. While materials obtained from polyol $\mathrm{M}_{\mathrm{w}}=1000 \mathrm{~g} /$ $\mathrm{mol},(\% \mathrm{NCO}=6 \%)$ have $38.7 \%$ of HS and DPS $=0.609$ $[13,18]$.

According to Table 2, the obtained DPS and DPM values are related both to the $[\mathrm{NCO}] /[\mathrm{OH}]$ molar ratio and the length of the polyurethane flexible segment. With the highest 
Table 2 Degrees of phase separation and phase mixing calculated on the basis of data obtained by deconvolution of absorption bands occurring in the carbonyl region for prepared bio-based polyurethanes

\begin{tabular}{lllllllr}
\hline Samples & Location $\left(\mathrm{cm}^{-1}\right)$ & Fraction $(\%)$ & Location $\left(\mathrm{cm}^{-1}\right)$ & Fraction $(\%)$ & $\mathrm{A}_{1703} / \mathrm{A}_{1730}$ & DPS & DPM \\
\hline PO3G1000_0.95 & 1699.51 & 83.23 & 1729.38 & 16.77 & 4.963 & 0.832 & 0.168 \\
PO3G2700_0.95 & 1698.22 & 86.18 & 1729.60 & 13.82 & 6.235 & 0.861 & 0.139 \\
PO3Gmix_0.9 & 1699.00 & 81.79 & 1728.62 & 18.21 & 4.489 & 0.817 & 0.183 \\
PO3Gmix_0.95 & 1698.65 & 80.64 & 1729.29 & 19.36 & 4.165 & 0.806 & 0.194 \\
PO3Gmix_1.0 & 1699.40 & 78.35 & 1729.27 & 21.65 & 3.618 & 0.783 & 0.217 \\
\hline
\end{tabular}

content of hard segments, the smallest degree of phase mixing was achieved. In general, it is assumed that the hydrogen bonds of carbonyl groups occur between the hard segments of the polymer chains, and the higher the number of bonds, the greater the phase separation is. On the other hand, the resulting hydrogen bonds between the hard and soft segments contribute to the mixing of the phases [10].

However, it is visible dependence between the content of bounded carbonyl groups, content HS, and the degree of DPS and DPM in TPUs obtained from prepolymers mixture. For these materials, the degree of phase separation decreased with increasing $[\mathrm{NCO}] /[\mathrm{OH}]$ molar ratio, and decreasing content of HS.

According to the literature, value of DPS is strongly dependent on the content of hard segments, if materials were prepared with using the same monomers. Materials with higher HS contents are characterized by better microphase separation, due to the increased long-range connectivity of hard segments, which can cause the formation of interconnected hard phase [18]. On the other hand, for materials prepared with using polyol with different molecular weight, the length of polyols had more effect on the DPS, than content of HS [29]. In our previous work, we prepared bio-based TPUs with using similar monomers (PO3G, MDI, Bio-BDO and Bio-PDO). Materials has the different content of HS. Materials were synthesized via two-step method. The concentration of NCO in the prepolymers was equal 6, 7 and $8 \%$. Materials, which had highest content of HS (about 44\%), showed a highest degree of phase separation (DPS equal 0.720) [18]. In this work, materials coded PO3G1000_0.95 have 49.4\% of HS and showed higher DPS, than materials prepared in our previous work. What confirms our conclusions.

Bistric et al. [30] prepared poly(ether-urethane)s based on diphenyl methane-4,4'-diisocyanate, poly(tetramethylene) glycol $(\mathrm{Mw}=1000 \mathrm{~g} / \mathrm{mol})$ and 1,4-butanodiol. Materials had 34 and $51 \%$ of HS and showed from 0.61 to 0.69 of DPS, respectively. This dependences was confirmed by Niemczyk et al. [31]. Jouibari et al. [32] synthesized poly(etherurethane)s, which showed 0.7 of DPS value. Fuensanta et al. [33] synthesized thermoplastic polyurethane coatings with mixture of polyethers. They showed, that the structure and microphase separation in strongly dependent on the content of hard segments and the length of used polyol.

\section{Thermal Properties}

Figures 4 and 5 show TG and DTG thermograms of samples synthesized at different $[\mathrm{NCO}] /[\mathrm{OH}]$ molar ratio using mixture of prepolymers and at the same $[\mathrm{NCO}] /[\mathrm{OH}]$ molar ration but differing in the structure of soft segments, respectively. According to the literature, two main stages of degradation process can be distinguished in all prepared TPUs $[28,34]$. At DTG curves presented in Fig. 5, maximum rate of weight loss occurred around temperatures from 330 to $342{ }^{\circ} \mathrm{C}$ corresponds to urethane bonds decomposition, whereas from 422 to $437{ }^{\circ} \mathrm{C}$ is related to polyetherol degradation process. The third, visible only on the DTG curves and taking place at a temperature close to $505{ }^{\circ} \mathrm{C}$ is probably contingent on breaking $\mathrm{C}-\mathrm{C}$ bonds $[35,36]$. The same can be seen on the curves shown in Fig. 4. The PO3Gmix_0.95 behavior during thermal decomposition is similar to PO3G1000_0.95 and PO3G2700_0.95, as shown in Fig. 5.

Detailed data from thermal analysis is summarized in Table 3. As it can be seen, PO3Gmix_0.95 is characterize

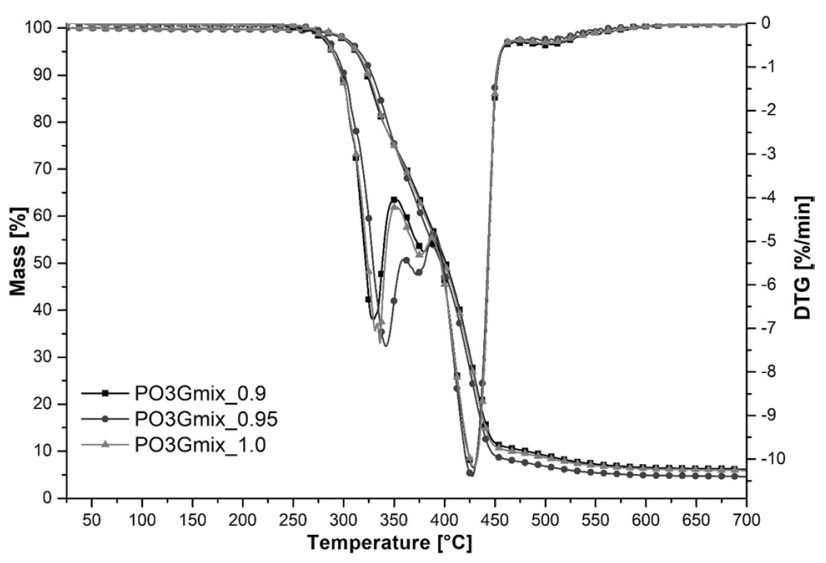

Fig. 4 TGA and DTG results for thermoplastic poly(ether-urethane)s synthesized from the polyols mixture at different $[\mathrm{NCO}] /[\mathrm{OH}]$ molar ratio 


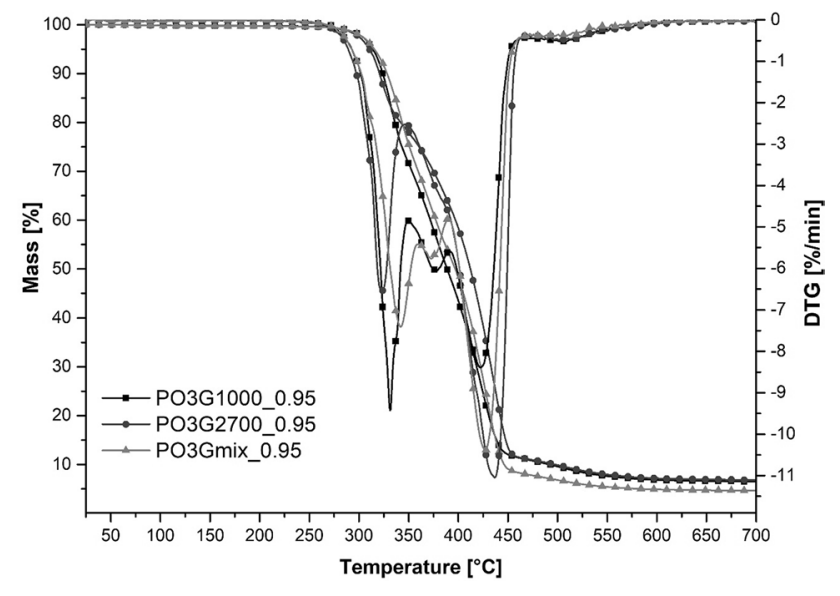

Fig. 5 TGA and DTG results for thermoplastic poly(ether-urethane)s synthesized with the use of different prepolymers

by the best thermal stability in the initial stage of decomposition. Thus in PO3Gmix_0.95 higher temperatures are needed in order to obtain 5 and $10 \%$ weight loss than in other materials. Therefore, from the thermal properties point of view, it is advantageous to use prepolymers mixture composition. This relationship is reversed in the second degradation stage where the decomposition of soft segment appears. Then, the temperature of $50 \%$ weight loss is $396.8^{\circ} \mathrm{C}$ and is lower compared to PO3Gmix_0.9 and PO3Gmix_0.95. The same model can be attributed to PO3G1000_0.95 and PO3G2700_0.95 samples, considering that the temperature at 5 and $10 \%$ weight loss is higher for PO3G1000_0.95, while for 50 and $90 \%$ weight loss it takes a lower value than for PO3G2700_0.95. Finally, practically complete degradation is the fastest for PO3Gmix_0.95 and the char yield reached the lower value equal to $4.6 \%$. It was noticed that, materials about molar ratio of $[\mathrm{NCO}] /[\mathrm{OH}]$ equal 0.95 , showed the relationship between content of HS and char residue. With the increasing content of $\mathrm{HS}$, the char residue decreasing. Likely, the char yield value is also highly connected with the length of used polyols. Sample prepared with using polyol PO3G2700 showed the highest char yield. As is knows the thermal decompositions of soft segments begins after the decomposition of HS.

However, TPUs obtained with using two different prepolymers showed different trend. In this case, the increase in the HS content caused a decrease char residue. It was found, that the molar ratio of the $[\mathrm{NCO}] /[\mathrm{OH}]$ groups has more affected on the char yield, than content of HS [37]. Only if materials are prepared with using the same monomers and differ only molar ratio of $[\mathrm{NCO}] /[\mathrm{OH}]$ groups.

A detailed description of the degradation processes is provided by thermogravimetric analysis (TGA) coupled with Fourier transform infrared spectroscopy (FTIR). An unquestionable advantage of this technique is the possibility of continuous monitoring of degradation products by infrared spectrums registration $[23,38]$ TGA-FTIR analysis provides both qualitative and quantitative information on the released volatile decomposition products, and also informs about the change in sample mass as a function of time and temperature $[34,39,40]$. The combination of both techniques allows for a more precise interpretation of the processes mechanisms occurring during materials decomposition rather than conducting separate analyzes [38, 41].

\section{Dynamic Mechanical Thermal Analysis}

Dynamic mechanical thermal analysis allows to determine TPUs ability to store and dissipate the mechanical energy supplied during material deformation. Knowledge of storage modulus $\left(\mathrm{E}^{\prime}\right)$ provides information about the material stiffness, while damping factor ( $\tan \delta$ ) about the mobility of polymer macromolecules and microphase morphology [42]. The change of $E^{\prime}$ and $\tan \delta$ as a function of temperature is shown in Figs. 6 and 7. The exact data is also presented in Table 4, where the maximum temperature of $\tan \delta$ was assumed as a soft segments glass transition temperature $\left(\mathrm{T}_{\mathrm{SS}}\right)$.

The synthesized materials showed two thermal transitions, that is, the glass transition temperature of soft segments and the glass temperature of hard segment $\left(\mathrm{T}_{\mathrm{HS}}\right)$. The graphs show a clear decrease in the storage modulus above $-50^{\circ} \mathrm{C}$. This phenomenon is caused by a significant increase in the mobility of polymer chain segments during glass transition [36, 42]. The transformation from the glassy state into rubbery state occurs in a similar temperature range for mixtures of prepolymers. In this case, there is a slight decrease in $\mathrm{T}_{\mathrm{SS}}$ from $-36.67{ }^{\circ} \mathrm{C}$ to $-33.64{ }^{\circ} \mathrm{C}$ as the $[\mathrm{NCO}] /[\mathrm{OH}]$ molar ratio change from 0.9 to 1.0 . This dependence can be explained by an increased degree
Table 3 The temperature of weight loss and chard yield obtained from thermal analysis of TPUs samples

\begin{tabular}{llllll}
\hline Samples & $\mathrm{T}_{5 \%}\left({ }^{\circ} \mathrm{C}\right)$ & $\mathrm{T}_{10 \%}\left({ }^{\circ} \mathrm{C}\right)$ & $\mathrm{T}_{50 \%}\left({ }^{\circ} \mathrm{C}\right)$ & $\mathrm{T}_{90 \%}\left({ }^{\circ} \mathrm{C}\right)$ & Char yield $(\%)$ \\
\hline PO3G1000_0.95 & 314.0 & 323.0 & 388.7 & 491.6 & 6.5 \\
PO3G2700_0.95 & 310.5 & 320.7 & 412.1 & 497.4 & 6.8 \\
PO3Gmix_0.9 & 312.1 & 323.4 & 401.4 & 481.1 & 6.2 \\
PO3Gmix_0.95 & 315.5 & 328.3 & 396.8 & 466.2 & 4.6 \\
PO3Gmix_1.0 & 312.9 & 324.4 & 400.1 & 466.6 & 5.9 \\
\hline
\end{tabular}




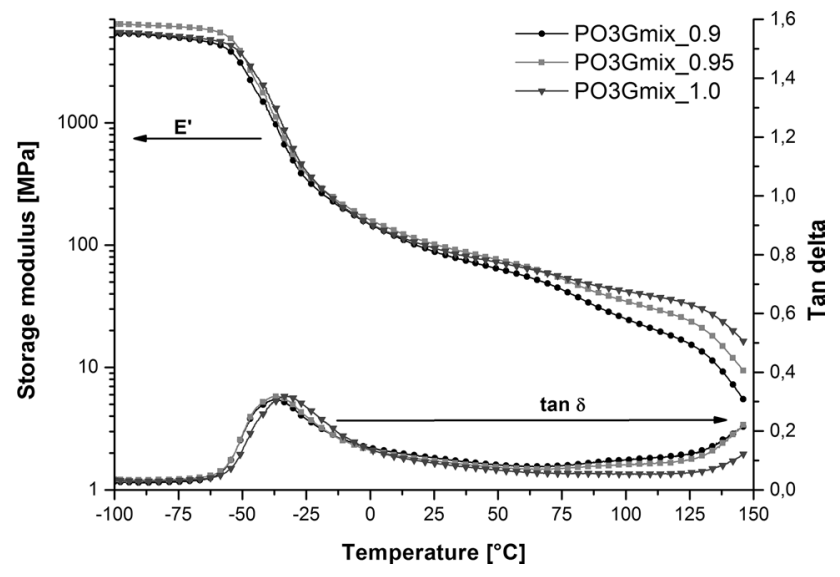

Fig. 6 DMTA thermograms presenting the dependence of the storage modulus and $\tan \delta$ as a function of temperature for TPUs obtained from the mixture of prepolymers

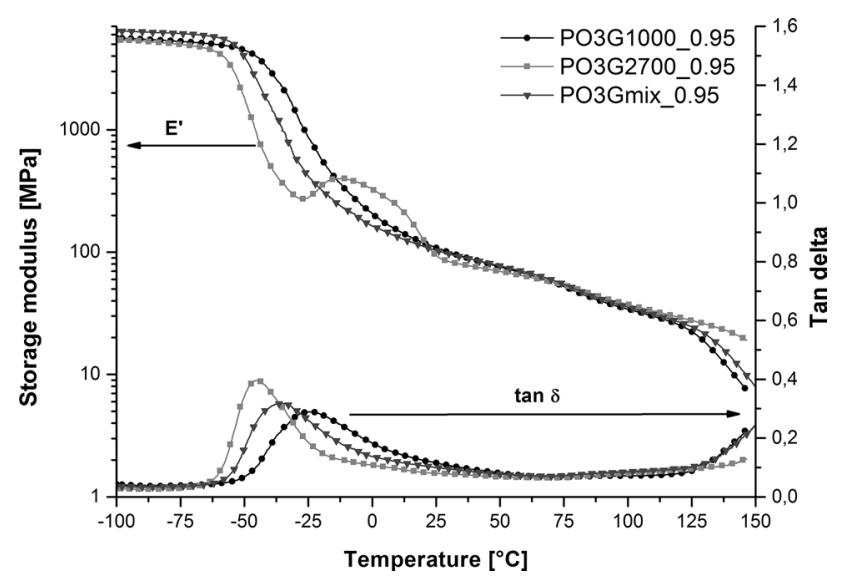

Fig. 7 DMTA thermograms presenting the dependence of the storage modulus and $\tan \delta$ as a function of temperature for TPUs obtained with different prepolymers

of phase separation in PO3Gmix_0.9, which results in the lowest $\mathrm{T}_{\mathrm{SS}}$ value $[43,44]$. Thus, the change in $\mathrm{T}_{\mathrm{SS}}$ indicates the mutual relationship between morphology and thermal properties of thermoplastic bio-polyurethanes. The correlation between morphology and $\mathrm{T}_{\mathrm{SS}}$ is also visible in samples synthesized with the molar ratio $[\mathrm{NCO}] /[\mathrm{OH}]$ equal to 0.95 . With increasing the length of the polyol, materials showed the lower $\mathrm{T}_{\mathrm{SS}}$ value, which is caused the higher DPS in this materials. What has been found in the FTIR analysis. Undoubtedly, the molar mass of the soft segments affects the DMA properties $\left(\mathrm{T}_{\mathrm{SS}}, \mathrm{T}_{\mathrm{HS}}, \tan \delta, \mathrm{E}^{\prime}\right)$, which is also confirmed by literature reports $[45,46]$. The data show that PO3Gmix_0.95 takes an intermediate $\mathrm{T}_{\mathrm{SS}}$ value between PO3G1000_0.95 and PO3G2700_0.95. Therefore, the highest glass transition temperature of PO3G1000_0.9 can be associated with the content of hard segments occurring in the highest amount in this sample, which is why the $\tan \delta$ peak is the broadest in comparison to other samples. For prepared TPUs the storage modulus was still decreasing at temperatures above $70{ }^{\circ} \mathrm{C}$, which can be related to the $\mathrm{T}_{\mathrm{HS}}$. The materials coded as PO3G1000_0.95, PO3Gmix_0.9 and PO3Gmix_0.95 showed clearer transition at temperature above $75{ }^{\circ} \mathrm{C}$, than samples coded as PO3G2700_0.95 and PO3Gmix_1.0. This observation is connected to higher content of hard segments in samples (PO3G1000_0.95, PO3Gmix_0.9 and PO3Gmix_0.95). According to the literature, TPUs showed the $\mathrm{T}_{\mathrm{HS}}$ of $<100{ }^{\circ} \mathrm{C}$, and the melting temperature of $\mathrm{HS}$ of $>100{ }^{\circ} \mathrm{C}[13,47]$.

Considering the storage modulus of bio-based poly(etherurethane)s synthesized from the prepolymers mixture, it is concluded that the PO3Gmix_0.95 sample has the highest stiffness, which is associated with the highest $\mathrm{E}^{\prime}$ value at room temperature. The same applies to the module at the glass transition temperature. The value of $\mathrm{E}^{\prime}$ is equal to $1024 \mathrm{MPa}$ at $\mathrm{T}_{\mathrm{SS}}$ and drops to $103.4 \mathrm{MPa}$ at $25^{\circ} \mathrm{C}$. Moreover, the difference between the modules for PO3Gmix_1.0 is smaller than for PO3Gmix_0.9 [44]. It should also be noted that storage modulus at $\mathrm{T}_{\mathrm{SS}}$ is the highest for the sample encoded as PO3Gmix_0.95 from all synthesized materials and this is the only value exceeding $1000 \mathrm{MPa}$. Moreover, the E' value at room temperature for materials prepared from mixture of prepolymers is found between the values obtained for PO3G1000_0.95 and PO3G2700_0.95 equal to $108.7 \mathrm{MPa}$ and $88.7 \mathrm{MPa}$, respectively. This can be correlated with the content of hard segments and soft segment molecular weight. Materials based on polyols PO3G1000 displayed the shortest and temperature sensitive rubbery plateau as the temperature increase, than materials encoded as PO3G2700_0.95. This is due to higher microphase
Table 4 Summary of the dynamic mechanical analysis carried out for bio-based thermoplastic poly(etherurethane)s

\begin{tabular}{llccl}
\hline Samples & $\mathrm{T}_{\mathrm{gSS}}\left({ }^{\circ} \mathrm{C}\right)$ & $\tan \delta$ & $\begin{array}{l}\mathrm{E}^{\prime} \text { at a room temperature } \\
(\mathrm{MPa})\end{array}$ & $\mathrm{E}^{\prime}$ at $\mathrm{T}_{\mathrm{gSS}}(\mathrm{MPa})$ \\
\hline PO3G1000_0.95 & -24.29 & 0.29 & 108.7 & 828 \\
PO3G2700_0.95 & -45.19 & 0.40 & 93.4 & 920 \\
PO3Gmix_0.9 & -36.67 & 0.31 & 88.7 & 951 \\
PO3Gmix_0.95 & -35.25 & 0.32 & 103.4 & 1024 \\
PO3Gmix_1.0 & -33.64 & 0.32 & 94.4 & 827 \\
\hline
\end{tabular}


separation in sample prepared with using polyol about higher molecular weight.

In Fig. 7, one can observe that the shape of $\tan \delta$ is clearly different for all synthesized materials. This proves that the chemical structure of the used prepolymer has a significant impact on the energy absorbing capability. As mentioned in the literature, the internal energy dissipation increases during the glass transition of polymer. This is also accompanied by an increase in internal friction, which is greater for higher $\tan \delta$ values [48]. Due to the very high $\tan \delta$ value, the best damping properties can be attributed to the sample PO3G2700_0.95, for which the content of hard segments is the lowest. It is known that polyurethanes hard segments are characterized by limited mobility, while soft segments are flexible and have great freedom of movement. Thus, in a material encoded as PO3G2700_0.95, a larger number of molecular segments can move freely than in other samples, which causes the increase of internal friction and the absorption of more energy. Summarizing, the length of the polyol has effect on the damping properties. With increasing the length of the polyol, materials possess higher of internal friction, which causes the increase the absorption energy. In materials obtained with different $[\mathrm{NCO}] /[\mathrm{OH}]$ molar ratios (Fig. 6), no critical differences in damping were noted.

\section{Mechanical Properties}

Mechanical properties of bio-based thermoplastic polyurethanes are shown in Table 5. The table summarizes such properties as: tensile strength $\left(\mathrm{TS}_{\mathrm{b}}\right)$, elongation at break $\left(\mathrm{E}_{\mathrm{b}}\right)$, Young's modulus and hardness $\left(\mathrm{H}^{\circ} \mathrm{ShD}\right)$. Based on the obtained data, it can be noticed that the tensile strength and elongation at break increase with increasing [NCO]/ $[\mathrm{OH}]$ molar ratio. Additionally, the samples of materials synthesized from PO3G with an average molecular weight of $1000 \mathrm{~g} / \mathrm{mol}$ are characterized by the best strength properties. In this case, the tensile strength and the elongation at break is equal to $10.9 \mathrm{MPa}$ and $258 \%$, respectively. This is due to the highest content of hard segments. As reported in the literature, at high HS contents the ability of the polymer chains to orient and crystallize under stress in amorphous SS

Table 5 Mechanical properties (tensile strength, elongation at break, Young's modulus and hardness) of prepared TPUs

\begin{tabular}{lccll}
\hline Samples & $\mathrm{TS}_{\mathrm{b}}(\mathrm{MPa})$ & $\mathrm{E}_{\mathrm{b}}(\%)$ & $\begin{array}{l}\text { Young's } \\
\text { modulus } \\
(\mathrm{MPa})\end{array}$ & $\mathrm{H}\left({ }^{\circ} \mathrm{ShD}\right)$ \\
\hline PO3G1000_0.95 & $10.9 \pm 1.2$ & $258 \pm 42$ & $42.1 \pm 0.8$ & $36.2 \pm 0.7$ \\
PO3G2700_0.95 & $10.6 \pm 0.8$ & $332 \pm 67$ & $34.9 \pm 1.1$ & $30.5 \pm 0.6$ \\
PO3Gmix_0.9 & $5.0 \pm 0.2$ & $41 \pm 4$ & $35.5 \pm 2.2$ & $28.2 \pm 0.5$ \\
PO3Gmix_0.95 & $7.2 \pm 0.4$ & $121 \pm 24$ & $36.8 \pm 1.0$ & $31.7 \pm 0.5$ \\
PO3Gmix_1.0 & $19.6 \pm 1.3$ & $592 \pm 32$ & $39.2 \pm 0.9$ & $34.6 \pm 0.6$ \\
\hline
\end{tabular}

segments is lower than for low HS contents, which is why $\mathrm{TS}_{\mathrm{b}}$ and $\mathrm{E}_{\mathrm{b}}$ assume low values [26].

Considering materials synthesized from a mixture of prepolymers with distinctive different molecular weights, it can be concluded that the highest $\mathrm{TS}_{\mathrm{b}}$ and $\mathrm{E}_{\mathrm{b}}$ corresponds to the PO3Gmix_1.0 sample. However, in this case the tensile strength and elongation at break are lower than for materials samples synthesized from polyols with a molecular weight of $1000 \mathrm{~g} / \mathrm{mol}$ or $2700 \mathrm{~g} / \mathrm{mol}$. By linking these relationships with the results presented in Table 2, it can be concluded that the reduced strength properties are the result of better soft and hard segments mixing.

Analyzing Young's modulus, it can be seen that it changes gradually with the molar ratio of NCO groups to $\mathrm{OH}$ groups from 35.5 to $39.2 \mathrm{MPa}$ for $[\mathrm{NCO}] /[\mathrm{OH}]=0.9$ and $[\mathrm{NCO}] /[\mathrm{OH}]=1.0$, respectively. With increasing molar ratio of $[\mathrm{NCO}] /[\mathrm{OH}]$ groups, the Young's modulus increasing. Moreover, the Young's modulus of thermoplastic polyurethanes obtained from the mixture of prepolymers is an intermediate value between Young's modulus of the reference materials. For example, the sample encoded as PO3G1000_0.95 showed Young's modulus of 42.1 MPa, while the values of $34.9 \mathrm{MPa}$ and $36.8 \mathrm{MPa}$ correspond to PO3G2700_0.95 and PO3Gmix_0.95 samples. The same relationship was obtained when measuring $\mathrm{E}^{\prime}$ at room temperature by DMTA method. Due to the highest content of HS, the highest value of Young's modulus showed the material coded as PO3G1000_0.95. This is caused by the limited mobility of hard segments in the TPUs with the higher content of HS. Summarizing, changes in the Young's modulus for all thermoplastic polyurethanes, both those with different $[\mathrm{NCO}] /[\mathrm{OH}]$ molar ratios, and those made of polyols with different molecular weights, can be attributed to the changing content of hard segments and $[\mathrm{NCO}] /[\mathrm{OH}]$ molar ratio.

A similar relationship was obtained after combining the hardness measurement results. The prepared materials based on a polyol having a molecular weight of $1000 \mathrm{~g} / \mathrm{mol}$ displayed the highest hardness compared to other samples, while the lowest hardness based on a polyol with a molecular weight of $2700 \mathrm{~g} / \mathrm{mol}$. Furthermore, the hardness of thermoplastic poly(ether-urethane)s synthesized from the prepolymers mixture increases with increasing molar ratio [NCO]/ $[\mathrm{OH}]$, and it varied from 35.5 to $39.2^{\circ} \mathrm{ShD}$. The reasons for such hardness results are the same as for strength properties.

Available literature presents a lot of studies about thermoplastic poly(ether-urethane)s. However, the most of materials were prepared with using others monomers than in this work. The most of presented TPUs based on poly ether polyols showed tensile strength in the range from 4 to $40 \mathrm{MPa}$, elongation at break up to $900 \%$, hardness up to $30^{\circ} \mathrm{ShD}$, and Young's modulus in the range from 18 to $60 \mathrm{MPa}$. Materials obtained in this work possess mechanical properties comparable with other presented works [7, 13, 18, 49, 49-52]. 


\section{Melt Flow Index and the Determination of Activation Energy}

The relationship between the obtained MFR and MVR and the temperature for thermoplastic poly(ether-urethane) $\mathrm{s}$ is shown in Table 6 and Fig. $8 \mathrm{a}$ and b. For all material samples, an increase in the melt flow rate can be observed as the test temperature increases. It is obvious that the $[\mathrm{NCO}] /[\mathrm{OH}]$ molar ratio affects the temperature, which is higher the higher its value. Thus, MFI values are gradually reduced as the $[\mathrm{NCO}] /[\mathrm{OH}]$ molar ratio used during chain extension increases. This is visible for PO3Gmix_0.9 and PO3Gmix_0.95 samples, where at $175{ }^{\circ} \mathrm{C}$ the MFR value is equal to $28.01 \mathrm{~g} / 10 \mathrm{~min}$ and $12.53 \mathrm{~g} / 10 \mathrm{~min}$, respectively. It can also be observed that for the sample encoded as PO3Gmix_1.0 the temperatures are much higher than for the other samples produced from the prepolymers mixture. According to the results in Table 6, it can be noticed that the MFI depends on the prepolymers and their mixture used during the synthesis of bio-based thermoplastic poly(ether-urethane)s. The highest temperatures, and therefore the smallest MFI were recorded for PO3G2700_0.95, while the highest values of the melt flow index were obtained for PO3G1000_0.95. For example, for the MFR tested at $170{ }^{\circ} \mathrm{C}$, a value of $10.46 \mathrm{~g} / 10$ min was reached for PO3G1000_0.95, whereas for PO3Gmix_0.95 it was $5.82 \mathrm{~g} / 10 \mathrm{~min}$. The obtained dependences are consistent with the hard segment concentration in prepared poly(etherurethane)s, which for the materials synthesized from the prepolymers mixture assumes an intermediate value. This is also reflected in the activation energies that increase as the $[\mathrm{NCO}] /[\mathrm{OH}]$ molar ratio increases, as well as the increase in HS content in thermoplastic bio-polyurethanes.

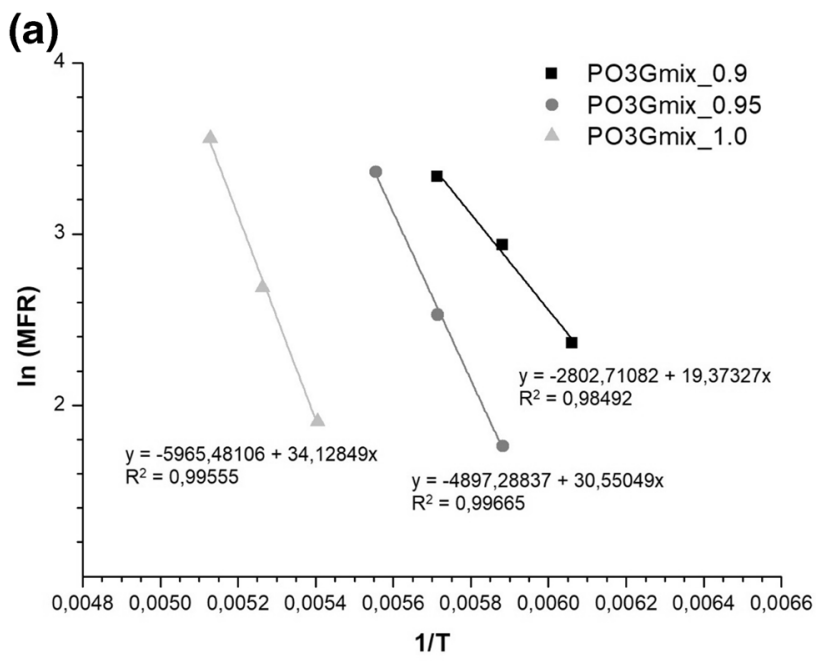

(b)

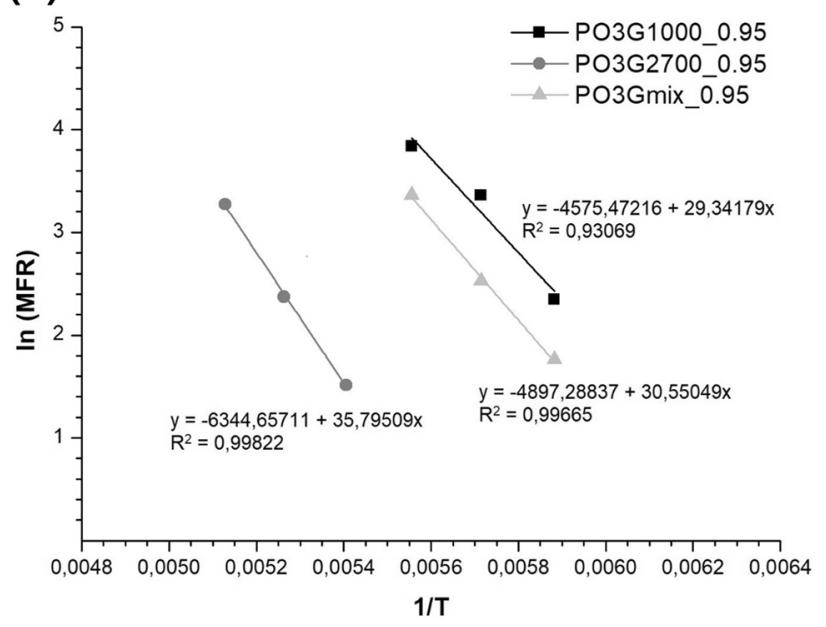

Fig. 8 Determination of energy activation for synthesized TPUs
Table 6 MFR and MVR of biobased TPUs

\begin{tabular}{|c|c|c|c|c|}
\hline Samples & Test conditions & $\begin{array}{l}\text { MFR } \\
(\mathrm{g} / 10 \mathrm{~min})\end{array}$ & $\begin{array}{l}\text { MVR } \\
\left(\mathrm{cm}^{3} / 10 \mathrm{~min}\right)\end{array}$ & $\mathrm{E}_{\mathrm{a}}(\mathrm{kJ} / \mathrm{mol})$ \\
\hline \multirow[t]{3}{*}{ PO3G1000_0.95 } & $170{ }^{\circ} \mathrm{C}, 5 \mathrm{~kg}$ & $10.46 \pm 0.7$ & $9.96 \pm 0.2$ & \multirow[t]{3}{*}{38.04} \\
\hline & $175^{\circ} \mathrm{C}, 5 \mathrm{~kg}$ & $28.78 \pm 0.4$ & $22.13 \pm 0.2$ & \\
\hline & $180^{\circ} \mathrm{C}, 5 \mathrm{~kg}$ & $46.45 \pm 1.8$ & $45.21 \pm 0.5$ & \\
\hline \multirow[t]{3}{*}{ PO3G2700_0.95 } & $185^{\circ} \mathrm{C}, 5 \mathrm{~kg}$ & $4.55 \pm 0.2$ & $4.57 \pm 0.2$ & \multirow[t]{3}{*}{52.75} \\
\hline & $190{ }^{\circ} \mathrm{C}, 5 \mathrm{~kg}$ & $10.72 \pm 0.7$ & $10.22 \pm 0.5$ & \\
\hline & $195^{\circ} \mathrm{C}, 5 \mathrm{~kg}$ & $26.42 \pm 0.5$ & $26.08 \pm 0.3$ & \\
\hline \multirow[t]{3}{*}{ PO3Gmix_0.9 } & $165^{\circ} \mathrm{C}, 5 \mathrm{~kg}$ & $10.63 \pm 0.5$ & $10.16 \pm 0.4$ & \multirow[t]{3}{*}{23.30} \\
\hline & $170{ }^{\circ} \mathrm{C}, 5 \mathrm{~kg}$ & $18.84 \pm 0.2$ & $18.53 \pm 0.2$ & \\
\hline & $175^{\circ} \mathrm{C}, 5 \mathrm{~kg}$ & $28.01 \pm 0.2$ & $25.78 \pm 1.3$ & \\
\hline \multirow[t]{3}{*}{ PO3Gmix_0.95 } & $170{ }^{\circ} \mathrm{C}, 5 \mathrm{~kg}$ & $5.82 \pm 0.5$ & $5.46 \pm 0.8$ & \multirow[t]{3}{*}{40.72} \\
\hline & $175^{\circ} \mathrm{C}, 5 \mathrm{~kg}$ & $12.53 \pm 0.8$ & $12.40 \pm 0.7$ & \\
\hline & $180^{\circ} \mathrm{C}, 5 \mathrm{~kg}$ & $28.87 \pm 0.9$ & $27.50 \pm 1.1$ & \\
\hline \multirow[t]{3}{*}{ PO3Gmix_1.0 } & $185^{\circ} \mathrm{C}, 5 \mathrm{~kg}$ & $6.72 \pm 0.1$ & $6.54 \pm 0.3$ & \multirow[t]{3}{*}{49.60} \\
\hline & $190{ }^{\circ} \mathrm{C}, 5 \mathrm{~kg}$ & $14.68 \pm 0.6$ & $14.53 \pm 0.6$ & \\
\hline & $195^{\circ} \mathrm{C}, 5 \mathrm{~kg}$ & $35.14 \pm 1.4$ & $36.14 \pm 1.3$ & \\
\hline
\end{tabular}




\section{Conclusion}

The mixture prepolymers allowed for the successful production of thermoplastic poly(ether-urethane)s via a two-step method. These materials possess a higher thermal stability and thermomechanical properties in comparison to references samples from one prepolymer.

The structure analysis by FTIR method confirmed that the mixture of prepolymers, molar ratio of $[\mathrm{NCO}] /[\mathrm{OH}]$ group, and the molecular weight of used bio-based polyol affect the degree of microphase separation and the number of hydrogen bonds of prepared bio-based thermoplastic poly(ether-urethane)s. The highest degree of separation showed of TPU coded as a PO3G2700_0.95. All produced materials are characterized by good phase separation, which reaches over $70 \%$. Furthermore, our experiments provide evidence for the new proposed method has significant impact on the properties materials especially thermal stability and thermomechanical properties of the prepared materials. The sample PO3Gmix_0.95 is characterize by the best thermal stability in the initial stage of decomposition, then from the thermal properties point of view, it is advantageous to use prepolymers mixture composition. Thermomechanical properties strongly depend on the HS content, molecular weight of polyol, and $[\mathrm{NCO}] /[\mathrm{OH}]$ molar ratio. Thus, the changes indicates the mutual relationship between morphology and thermal properties of thermoplastic bio-polyurethanes. It should also be noted that storage modulus at TS is the highest for the sample encoded as PO3Gmix_0.95 from all synthesized materials and this is the only value exceeding $1000 \mathrm{MPa}$. Additionally, $\tan \delta$ is clearly different for all synthesized materials. This proves that the chemical structure of the used prepolymer has a significant impact on the energy absorbing capability. It has been presented that the energy activation and value of melt flow index are dependent on the amount of hydrogen bonds between the hard segments and degree microphase separation. This is also reflected in the activation energies that increase as the $[\mathrm{NCO}] /[\mathrm{OH}]$ molar ratio increases, as well as the increase in HS content in thermoplastic bio-polyurethanes. Materials coded PO3G2700_0.95 showed highest energy activation, due to the higher concentration of hydrogen bonds.

The conclusion is the mixture of different prepolymer allows to better control of properties materials. It was obtained materials about high mechanical properties, good melt flow index, and better thermal stability. We have demonstrated that the bio-based thermoplastic polyether-urethane)s can be obtained with using a mixture of two different prepolymers. Materials prepared from mixture prepolymers presents competitive dynamic mechanical properties and thermal properties compared to poly(ether-urethane)s obtained with using normal two-step synthesis. This new proposed method is simple, convenient and advantageous. This method is especially useful in obtained materials about higher thermal stability.

Acknowledgement The authors wish to thank BASF (Germany) and Allesa (Germany) for kindly providing bio-based 1.4-butanediol and bio-based polytrimethylene polyol.

Funding This work was supported by the National Science Centre, Poland [Grant Number 2017/27/N/ST8/02575].

\section{Compliance with Ethical Standards}

Conflict of interest The authors declare that they have no conflict of interest.

Open Access This article is distributed under the terms of the Creative Commons Attribution 4.0 International License (http://creativecommons .org/licenses/by/4.0/), which permits unrestricted use, distribution, and reproduction in any medium, provided you give appropriate credit to the original author(s) and the source, provide a link to the Creative Commons license, and indicate if changes were made.

\section{References}

1. Jutrzenka Trzebiatowska P, Santamaria Echart A, Calvo Correas T et al (2018) Prog Org Coat 115:41-48

2. Kosmela P, Zedler L, Formela K et al (2016) Chem Chem Technol 10:571-580

3. Parcheta P, Datta J (2017) Crit Rev Environ Sci Technol 47:1986-2016

4. Ramesh M, Palanikumar K, Reddy KH (2017) Renew Sustain Energy Rev 79:558-584

5. Błażek K, Datta J (2019) Crit Rev Environ Sci Technol 49:173-211

6. Gómez-Jiménez-Aberasturi O, Ochoa-Gómez JR (2017) J Chem Technol Biotechnol 92:705-711

7. Datta J, Kasprzyk P (2017) Polym Eng Sci 58:E14-E35

8. Datta J, Balas A (2003) J Therm Anal Calorim 74:615-621

9. Datta J, Łaski M, Kucinska-Lipka J (2007) Przem Chem 86:63-67

10. He Y, Xie D, Zhang X (2014) J Mater Sci 49:7339-7352

11. Eceiza A, Martin MD, De La Caba K et al (2008) Polym Eng Sci 48:297-306

12. Kulkarni P, Ojha U, Wei X et al (2013) J Appl Polym Sci 130:891-897

13. Kasprzyk P, Datta J (2018) Polym Eng Sci 58:E199-E206

14. Yilgor I, Yilgor E, Guler IG et al (2006) Polymer 47:4105-4114

15. Lei W, Fang C, Zhou X et al (2017) Thermochim Acta 653:116-125

16. Li W, Liu J, Hao C et al (2008) Polym Eng Sci 48:249-256

17. Simendic JB, Bjelovic Z, Tanasic LJ, Erceg T, Pavlicevic J, Aleksic V, Micic V (2016) XXIV international conference ecological truth, Eco-Ist'16, vol 6, p 177

18. Kasprzyk P, Datta J (2019) Polymer 160:1-10

19. Byczyński U, Dutkiewicz M, Maciejewski H (2014) Thermochim Acta 589:252-261

20. Chuang FS, Tsi HY, Chow JD et al (2008) Polym Degrad Stab 93:1753-1761

21. Głowińska E, Datta J (2016) Cellulose 23:581-592

22. Guerreiro SDC, João IM, Pimentel Real LE (2012) Polym Testing $31: 1026-1030$ 
23. Askari F, Barikani M, Barmar M et al (2015) Iran Polym J 24:783-789

24. Datta J, Kasprzyk P, Błażek K, Włoch M (2017) J Therm Anal Calorim 130:261-276

25. Datta J, Głowińska E (2014) Ind Crop Prod 61:84-91

26. Saralegi A, Rueda L, Fernández-D’Arlas B, et al (2013) Polym Int 62:106-115

27. Kojio K, Nakashima S, Furukawa M (2007) Polymer 48:997-1004

28. Liu T, Ye L, Liu Y, Nie F (2008) Plast Rubber Compos 37:331-340

29. Klinedinst DB, Yilgör I, Yilgör E et al (2012) Polymer 53:5358-5366

30. Bistričić L, Baranović G, Leskovac M, Bajsić EG (2010) Eur Polym J 46:1975-1987

31. Niemczyk A, Piegat A, Sonseca Olalla Á, El Fray M (2017) Eur Polym J 93:182-191

32. Sahebi Jouibari I, Haddadi-Asl V, Ahmadi H, Mirhosseini MM (2019) Polym Compos 5:2. https://doi.org/10.1002/pc.25250

33. Fuensanta M, Martín-Martínez JM (2018) Prog Org Coat 118:148-156

34. Pielichowski K, Leszczyńska A (2004) J Therm Anal Calorim 78:631-637

35. Xie F, Zhang T, Bryant $P$ et al (2019) Prog Polym Sci 90:211-268

36. Ryszkowska J, Auguscik M, Kuranska M et al (2017) Polimery/ Polymers 62:136-143

37. Pukánszky B, Bagdi K, Tóvölgyi Z et al (2008) Eur Polym J 44:2431-2438
38. Duan Y, Li H, Ye L, Liu X (2006) J Appl Polym Sci 99:3085-3092

39. Sun N, Liang Y, Xu Z et al (2013) J Polym Eng 33:337-344

40. Tudorachi N, Chiriac AP (2011) Polym Test 30:397-407

41. Chattopadhyay DK, Webster DC (2009) Prog Polym Sci 34:1068-1133

42. Nguyen Dang L, Le Hoang S, Malin M et al (2016) Eur Polym J 81:129-137

43. Barick A, Tripathy D (2012) J Appl Polym Sci 124:765-780

44. Fiorio R, Zattera AJ, Ferreira CA (2010) Polym Eng Sci 50:2321-2328

45. Castagna AM, Pangon A, Choi T et al (2012) Macromolecules 45:8438-8444

46. Piril Ertem S, Yilgor E, Kosak C et al (2012) Polymer 53:4614-4622

47. Sun $H$ (1993) Macromolecules 26:5924-5936

48. Xiao D, Zhao X, Feng Y et al (2010) J Appl Polym Sci 116:2143-2150

49. Abouzahr S, Wilkes GL (1984) J Appl Polym Sci 29:2695-2711

50. Abouzahr S, Wilkes GL, Ophir Z (1982) Polymer 23:1077-1086

51. Rogulska M, Kultys A, Olszewska E (2013) J Therm Anal Calorim 114:903-916

52. Rogulska M, Kultys A, Lubczak J (2015) J Therm Anal Calorim 121:397-410

Publisher's Note Springer Nature remains neutral with regard to jurisdictional claims in published maps and institutional affiliations. 